\title{
Research developments on glass structures under extreme loads
}

\author{
C. Bedon \\ University of Trieste, Trieste, Italy
}

\begin{abstract}
The increasingly use of glass in buildings certainly represents a new challenge for designers and researchers. On one side, the continuous development and innovation supports the development of novel solutions. At the same time, research studies and efforts are still required to optimize the safety levels and structural performances of this unconventional constructional material. Finally, a special care must be necessarily spent for the protection of glass structural elements and systems from the effects of potentially extreme design loads that may occur during their life-time (such as impact or explosive events, but also earthquakes, fire accidents and even excessive vibrations). In most of the cases, the major challenge comes from the mechanical (and even thermal) interaction of primary glass components with other constructional materials, like metal fasteners, and others. This paper gives evidence of some research developments and ongoing challenges.
\end{abstract}

\section{INTRODUCTION}

\subsection{Glass structures}

The industrialized use of glass in buildings as an effective load-bearing material for constructions is a relatively recent solution, compared to traditional and consolidated alternatives such as timber, steel, concrete and composites or masonry. On one hand, positive arguments in support of the large use in claddings and envelopes is related to the thermal, energy, light and aesthetic performance of glass. The same architectural trend that evolves towards the design and construction of geometrically complex solutions is another intrinsic support to further glass developments. Finally, the technological innovation in the building sector is also favorable to the use of transparent load-bearing components (Figure 1).

Besides, major challenges that are related to the use of glass in buildings are still associated to its basic mechanical properties, that make the design approach more challenging than other constructional materials. The relatively low tensile strength and tensile brittle behavior of glass as a material in load-bearing applications requires dedicated resistance verifications (especially in presence of holes or a long series of affecting parameters (Haldimann et al., 2008; CNR-DT 210/2013)). At the same time, the use of relatively small glass thicknesses to cover large surfaces in windows and facades make severe the need of serviceability deflection verifications, so as to ensure appropriate operational performances for glass members and structures.

The combination of the above aspects makes thus glass material itself the first potential responsible of high vulnerability for the occupants (Figure 2), given that both in the form of partition member or load-bearing component it is required to sustain loads, satisfy rigid performance metrics and optimally behave under mechanical or even climatic and thermomechanical loads. The designer is thus demanded to account for unfavorable basic material features and maximize the ensured safety levels. Even in presence of refined calculation 
a)

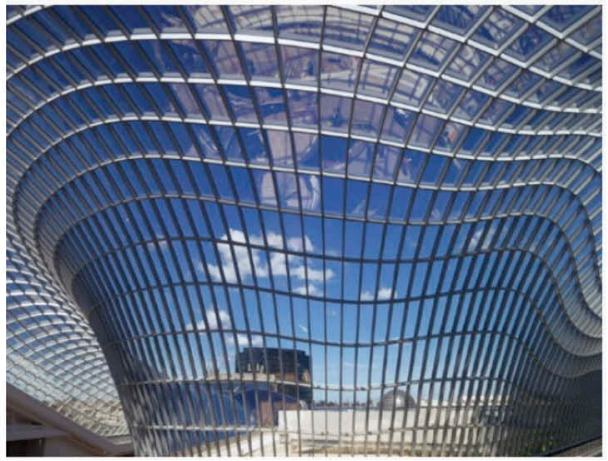

c)

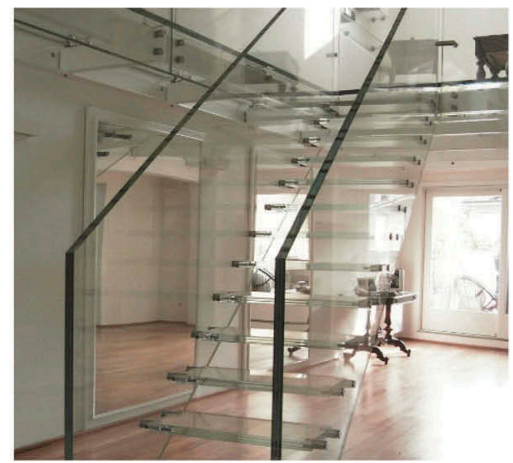

b)

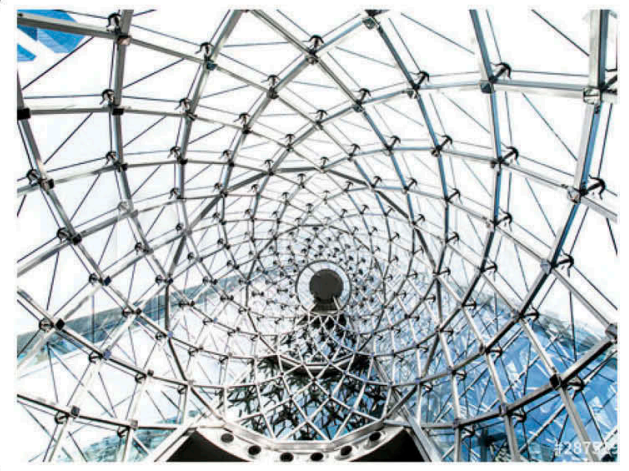

d)

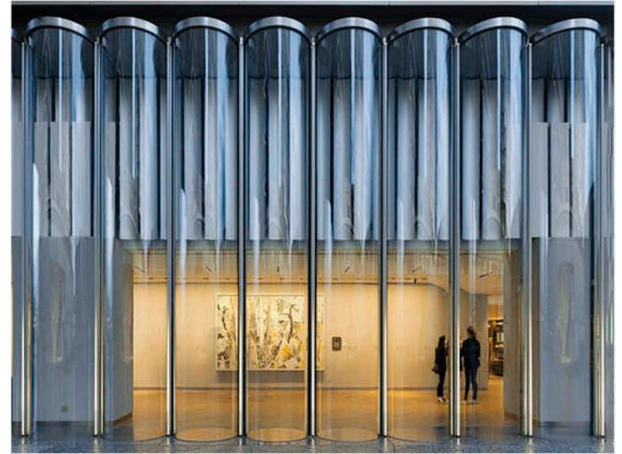

Figure 1. Structural glass applications in buildings: a) - b) roofs, c) stairs or d) facades.

a)

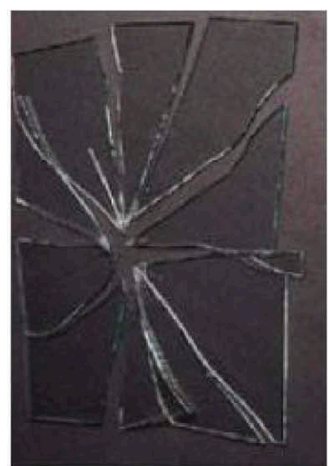

b)

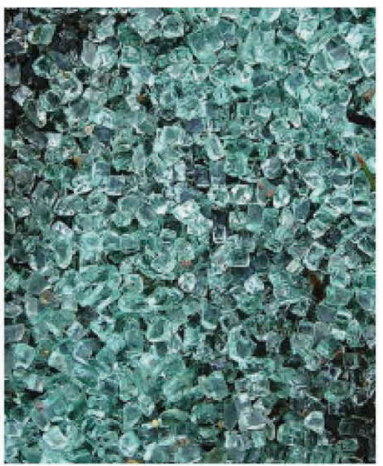

c)

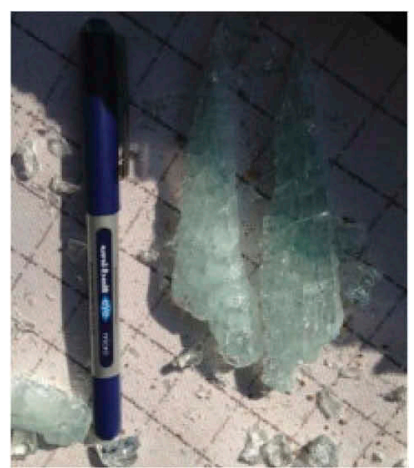

Figure 2. Selected examples of fractured glass: a) float glass; b) tempered glass and c) glass shatters due to explosion (figures reproduced from (Bedon et al., 2018)).

approaches and methods that can be based on the use of Finite Element (FE) or Computational Fluid Dynamics (CFD) numerical simulations, glass structures are often representative of a critical component in buildings and constructed facilities. This is true especially when extreme loading conditions are expected at the design stage, or could even occur over the lifetime of a given structural system. Glass windows and envelopes, in this regard, are required to act as the physical line of separation of indoor and outdoor spaces. Horizontal systems like roofs, floors, stairs are further required to offer even larger safety levels to the occupants. This 
is also the case of glass balustrades, when a potential risk of failure may occur. As a general rule, multidisciplinary approaches and specific fail-safe design criteria are necessarily required both under operational design loads and even more under critical conditions that may occur in a given life-time.

In this regard, design standards and technical documents are in continuous evolution and refinement (see for example the $\mathrm{prCEN} / \mathrm{TS} \mathrm{xxxx}-1$ and $\mathrm{prCEN} / \mathrm{TS} \mathrm{xxxx}-2$ documents) to support all the fundamental design and maintenance stages.

Besides, further research efforts are still required to optimize the existing design procedures, extend the available methods to general loading and boundary conditions of technical interest, or even adapt the existing methods to ongoing progress and innovation in the building sector.

\subsection{Extreme design loads for glass in buildings}

Even more than other constructional materials, glass members and systems should be properly designed with the maximization goal of safety, robustness, redundancy (CNR-DT 210/2013; $\mathrm{prCEN} / \mathrm{TS} \mathrm{xxxx}-1$; prCEN/TS $\mathrm{xxxx}-2$ ). The satisfaction of this requirements is a strategic task for the design and construction of attractive glass structures that can take advantage of human perceptions and emotions based on the material transparency (Figure 3a-b). Besides, major challenges are represented by extreme accidental events that can take the form of impacts (Kalamar et al., 2016; Zhang et al., 2020); explosive events (Figure 3c and (Bedon et al., 2018)); fire accidents (Figure 3d and (Bedon, 2017)) or vibrations (Section 2) and earthquakes (Section 3).

The two main requirements associated to structural safety of individual elements composed of glass include the Ultimate Limit State (ULS) and the Serviceability Limit State (SLS). The

a)

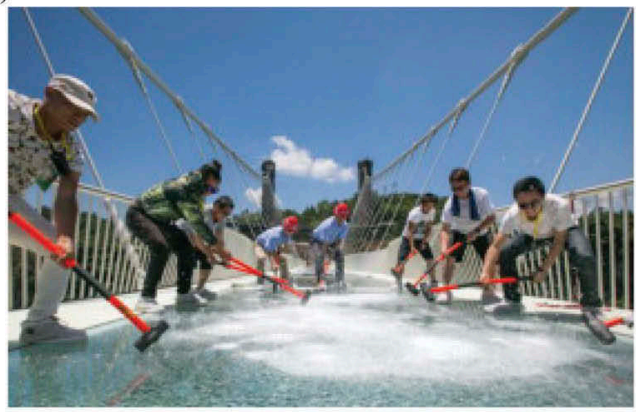

c)

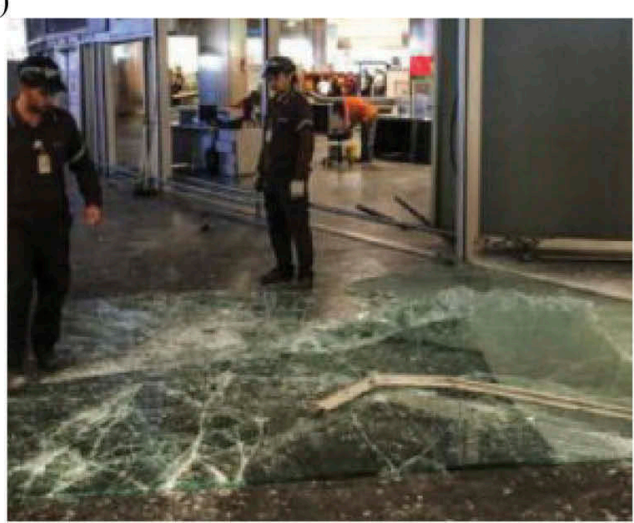

b)

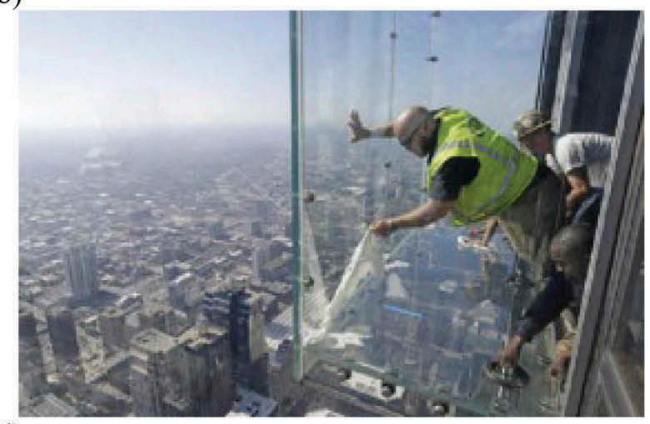

d)

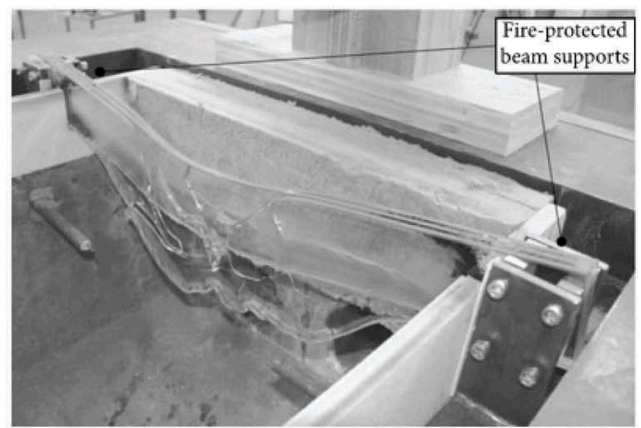

Figure 3. Structural glass applications in buildings: a) bridge; b) balcony; c) envelope collapse due to blast and d) laminated glass beam in fire testing (reproduced from (Bedon, 2017) under the terms and conditions of the Creative Commons Attribution (CC BY) license). 
first one ensures that structural elements have adequate strength to withstand the anticipated actions without fracture or stability loss, whereas the SLS requirements usually focus on deflections and vibrations, which might affect aesthetics, comfort of users or cause damage to other structural elements. The so-called Collapse Limit State (CLS) adopted by the Italian technical document CNR-DT 210/2013 represents a third level of analysis.

According to the fail-safe approach, it follows the need to account that an imponderable event can cause some glass components to fragment partially or completely. As such, it is required to ensure that even in this limit condition the glass element to verify can maintain enough load bearing capacity to carry permanent loads, and also a part of the variable loads that is consistent with the working conditions, thus preventing dangerous falls of material.

Accidental or man-made explosions are a critical condition for glass, given that they are typically characterized by a rapid and sudden release of energy in the form of shock wave, light, heat and sound. These shock waves consist of highly compressed air traveling at supersonic velocity.

When the shock waves hit the front surface of a structure or building, they are then reflected and amplified. Given an explosive event, the magnitude of the overall incident blast pressure is usually defined as a function of the equivalent charge weight of TNT, the geometry and stand-off distance from the centre of the charge to the wave front. The peak pressure of the compressed wave decays very rapidly, typically in times of the order of milliseconds. The initial compressive shock wave is followed by a vacuum as a result of gas and material being expelled rapidly from the point of detonation. For buildings and structural systems which are not designed to resist against blast, explosive events waves generally impinge on the external envelope, leading to the failure of glass windows and facades with the propagation of dangerous shards (Figures 2 and 3c). The use of laminated glass resisting sections can ensure a major absorption of input energy and protect people from severe shatters. The use of triple insulated glass units can be efficient (Sielicki et al., 2020). However, special benefit can be taken from the blast-resistant design of glass as well as by some available techniques for the mitigation of glass components (Zhang \& Bedon, 2017; Förch, 2020). Support can be taken from FE numerical analysis, once the design load features and the mechanical components are properly characterized (Larcher et al., 2016).

Fire accidents, as well as explosions, can severely affect the mechanical performance of a given glass member to verify (Figure 3d). The first issue, in this regard, arises from the progressive modification of glass state and material properties with the increase of imposed temperatures (Bedon, 2017). This result in a complex thermo-mechanical response in which first the stress peaks in glass migrate towards the cold regions, and the load-bearing members is still able for a while to sustain the imposed mechanical loads. Suddenly, as far as the temperature further increases, the glass member itself is not able to offer any kind of residual stiffness, thus leading to the final collapse/melting. Premature thermal shock can also occur in glass, thus experimental support should be preferred for the development of general numerical studies (Kozlowski et al., 2018; Sjöström et al., 2020). While special fire-resistant glass solutions are already distributed and used in practical design, these applications are limited to selected configurations (partition walls, barriers, doors) and the use of ordinary, soda-lime silica glass still prevails in constructed facilities.

As a general rule, special methods of analysis are required when for highly dynamic loads and/or temperature/humidity scenarios that may result in variations in the mechanical properties of materials in use. This is the case of glass but also of the viscoelastic bonding layers that are used for laminates, as well as secondary components in joints, etc. Selected examples reported in Figure 4 give evidence of current effects due to strain rate on the tensile and compressive strength of glass (Figures 4a-b), as well as of the vibration frequency effect on the shear rigidity of common interlayers (Figure 4c). Finally (Figure 4d). it is also important to analyze the local effect and the global performances due to soft layers that are typically interposed to glass and the restraining systems (especially metal frame members or point-fixings). 
a)

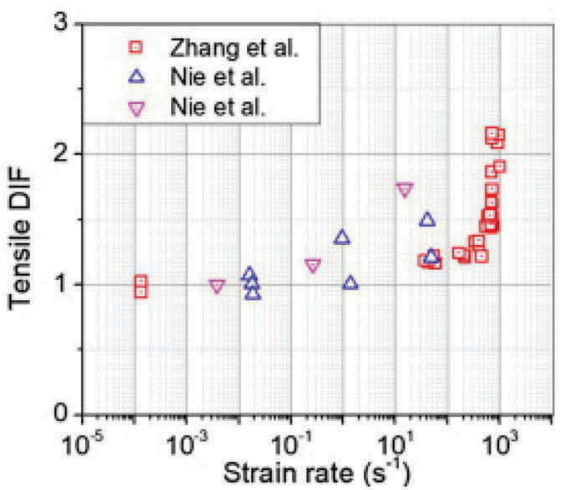

c)

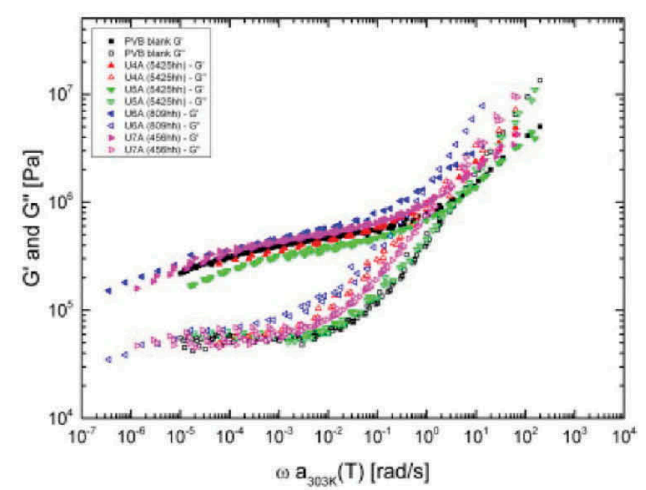

b)

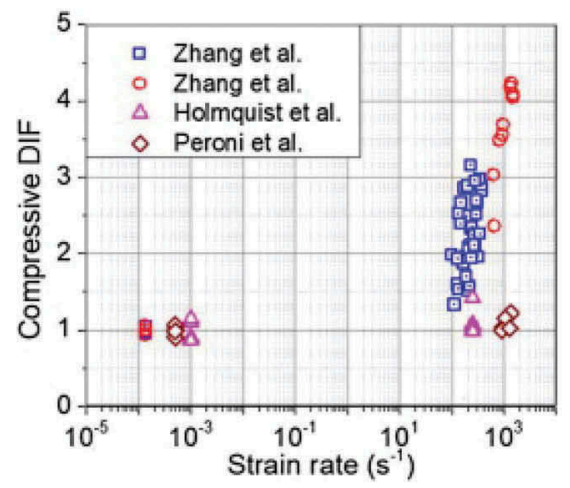

d)

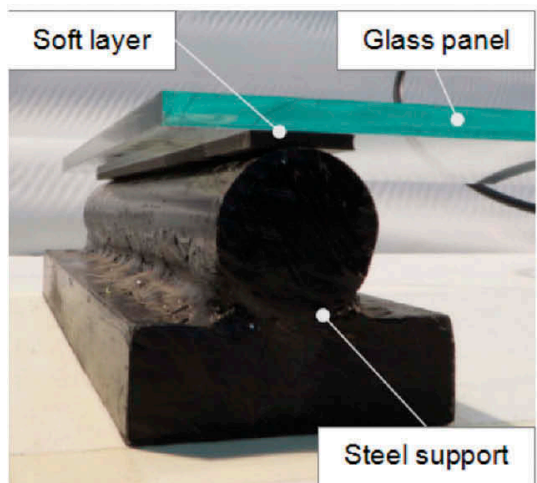

Figure 4. Examples of modification of material properties: a) tensile and b) compressive glass strength (dynamic increase) as a function of the imposed strain rate (figures reproduced from Bedon et al., 2018); c) shear stiffness modification in viscoelastic interlayers, as a function of the imposed vibration frequency (reproduced from (Bedon \& Fasan, 2019) under the terms and conditions of the Creative Commons Attribution (CC BY) license); d) local analysis of soft layer effects on the restraint and vibration response of glass members (reproduced from (Bedon et al., 2019) under the terms and conditions of the Creative Commons Attribution (CC BY) license).

\subsection{Fasteners for glass structures}

Under the effects of extreme design loads, the role of fasteners and restraints is even more strategic than under ordinary operational conditions. Any kind of energy dissipation, mitigation and protection of glass edges from premature stress peaks can take large benefit (or even severe magnification) from the connection detailing. This is especially the case of glass members and systems that are required to suffer for large/repeated displacements, as it is under seismic events.

Most of the existing studies and research projects of literature are in fact focused on the seismic assessment of specific constructional systems. This is the case of ordinary glass curtain walls, where glass panels are fully braced by continuous framing members, and merely intended as infill components. Several efforts have been also spent in the past for the design and analysis of glass structures with bolted connections, but only few research investigations are available for point-supported facades in earthquake-prone regions, with a focus on the intrinsic flexibility under in-plane seismic loads. The dissipation capacity of ordinary curtain walls under seismic events was partly assessed also in with the support of experiments, while an efficient, dissipative timber-glass composite shear wall was proposed in for earthquake resistant buildings.

In (Bedon \& Amadio, 2018), for example, it was demonstrated that even ordinary glass curtain walls can be efficiently involved in the dynamic response of multi-storey buildings under seismic events, as well as multi-hazards in general. Based on special dissipative connectors, the 
feasibility of a "distributed-Tuned Mass Damper (TMD)" concept was numerically explored, giving evidence of certain potential benefits for both the primary building and also for the glass facade components. The same research study highlighted, however, the need of a detailed design of the involved connectors, to avoid inconsistent stress/displacement demands under seismic loads.

Certainly, the design of fasteners and anchoring systems represent a key challenge for glass structures in seismic regions. The primary goal of design is in fact to prevent stress peaks in glass, due to the seismic deformations of the main structure they belong to, and large deformation capacity.

\section{SEISMIC EVENTS}

Among others, seismic events still represent for glass structures a critical operational condition that should be properly addressed at the design stage. Induced accelerations and vibrations can in fact be responsible of severe stress peaks that the glass components should be able to withstand. At the same time, both for stand-alone glass assemblies or for interventions in existing primary buildings that are made of other constructional typologies/materials, the glass members should be able to accommodate the required displacement demand. Such a request must be fulfilled for glass components but also for the restraints in use. This is highly demanding for a material that is characterized by a well-known tensile brittle behaviour, as well as by a high sensitivity to local effects that progressively reduce the expected design tensile strength (Section 1).

Some criticalities may further derive from the presence of point-fixings and holes in glass that require the local analysis of stress concentrations, or to the design of (even secondary) glass systems that are expected to take place in strategic buildings. The study reported in (Bedon et al., 2019), in this regard, points out such a condition.

The case study example is also summarized in Figure 5, and consists of a glass partition assembly composed of double laminated glass (LG) walls with metal point-fixings. The partition assembly was designed in the early 2018, to take place in an historical building in Trieste (Italy), and to protect one of its entrances from wind and rain exposure (Figure 5). The building, known as "Ferdinandeo Palace" is one of the most prestigious monuments of the city (erected in 1858 in honor of the Emperor Ferdinand I of Habsburg), and since 1999 hosts the MIB School of Management.

The 3D glazed assembly in Figure 5 covers up to $\approx 50$ square meters. The resisting section of each LG panel is composed of two, $6 \mathrm{~mm}$ thick fully tempered layers and a $1.52 \mathrm{~mm}$ thick, Poly-

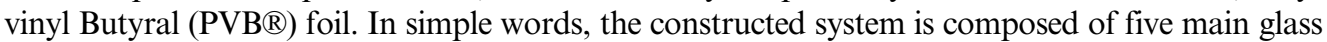
walls, with a nominal span in the range from $1.68 \mathrm{~m}$ to $2.65 \mathrm{~m}$. For these walls, the top height (in the range $4.3-4.65 \mathrm{~m}$ ) is obtained by means of two glass panels in the elevation of the structure.

The main feature of the design concept is represented by the minimization of metal fasteners and restraints to brace the system. A set of metal connectors was in fact chosen to erect the partition walls and provide an appropriate restraint in the elevation of the system. Several types of point-fixings were used, all of them composed of AISI 304 (EN 1.4301) and AISI 316 (EN 1.4436) steel types (Figures 5c and 5d).

Some of the steel point-fixings in use were realized in the form of bespoke joints able to fix the LG panels to the columns of the Palace. These bespoke joints-agreeing with and adapted from DP-44-100 devices from Metalglas ${ }^{\circledR}$ - consisted of a central M12 bolt and a steel solid section (with $42 \mathrm{~mm}$ the nominal diameter) for the main body and head. The total length of these devices (up to $180 \mathrm{~mm}$ ) was properly defined for each one of them, in order to accommodate the actual distance between the partition walls and the columns of the building.

Most importantly, a series of holes (with a diameter of $22 \mathrm{~mm}$ ) was also realized in the resisting section of the LG panels, to facilitate the installation of the partition system but also to ensure the presence of an appropriate gap with the M12 bolts. Under in-plane lateral forces due to seismic actions (or even wind), the case-study structural concept takes advantage of the "box-behaviour" and mechanical interaction of adjacent/orthogonal walls. As such, the 
a)

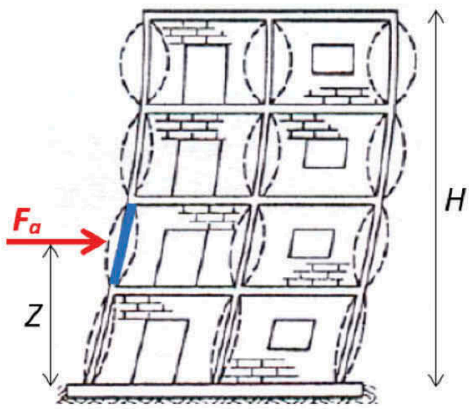

c)

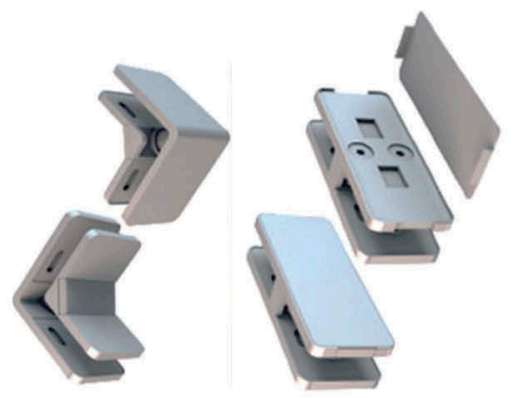

b)

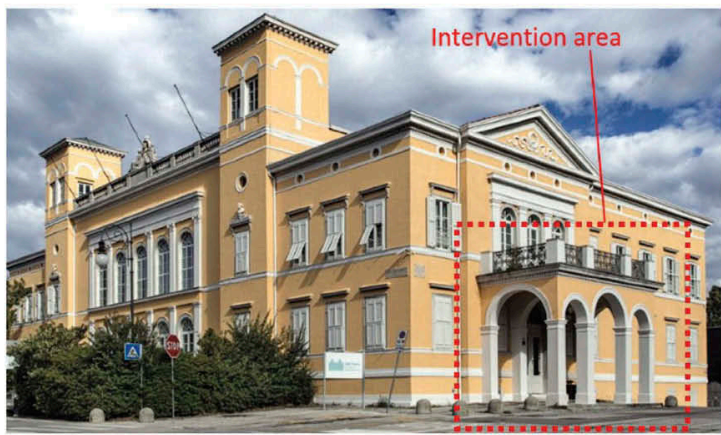

d)

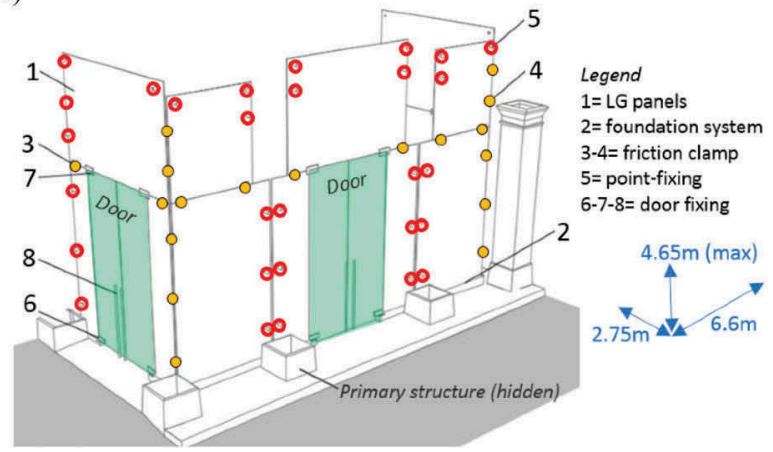

Figure 5. Seismic design of a secondary frameless glass system: a) local seismic force calculation; b) case-study intervention; c) examples of metal restraints in use and d) schematic representation of the final setup with evidence of the fastener type/position (figures reproduced from (Bedon et al., 2019) under the terms and conditions of the Creative Commons Attribution (CC BY) license).

analysis and verification of single glass walls (i.e., Figure 6a) requires appropriate considerations for the calculation of reaction forces transferred from one wall to the other. Lastly, the presence of glass holes needs the analysis of local stress peaks that are magnified due both to primary bending effects (Figure 6b) but also in-plane design loads/reaction forces.

\section{VIBRATIONS}

The vibration serviceability assessment of a given load-bearing system is known to represent a strategic step of design (EN 1990; ISO 10137). Besides the positive resistance and deflection verifications, a given system could be still weak in terms of comfort for the occupants, or even damage issues due to induced vibrations.

In the specific case of pedestrian systems composed of glass, the design challenge is even more complex rather than for slabs that are composed of traditional constructional materials. The structural mass, damping and stiffness are in fact key input parameters of the structure that are required to interact with a given moving load due to pedestrians (Figure 7).

While validated calculation methods are available since long in several technical documents and standards for the vibration serviceability analysis and assessment of concrete, steel, composite or timber slabs, this is not the case of structural glass solutions (Bedon \& Fasan, 2019). Literature approaches are in fact intrinsically verified and calibrated for the analysis of horizontal load-bearing members in which the mass is expected to be typically higher than the occupants (depending on the final destination of the system). Further, the typical range of vibrations for concrete, steel or timber slabs is also well defined and can be predicted with the support of simple mechanical models. 
a)

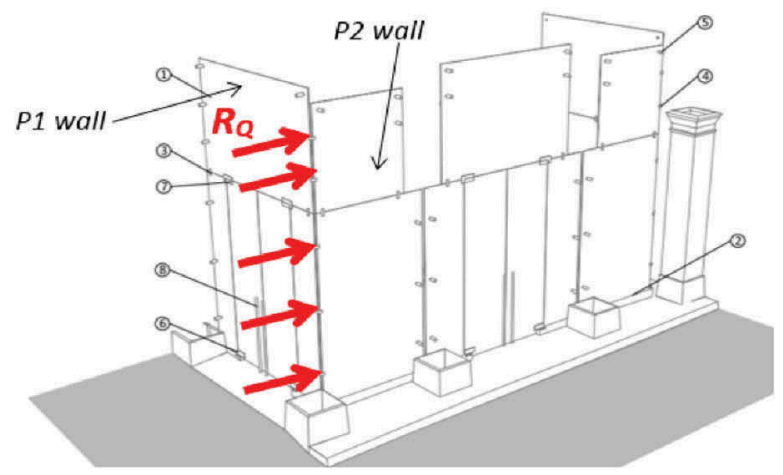

b)

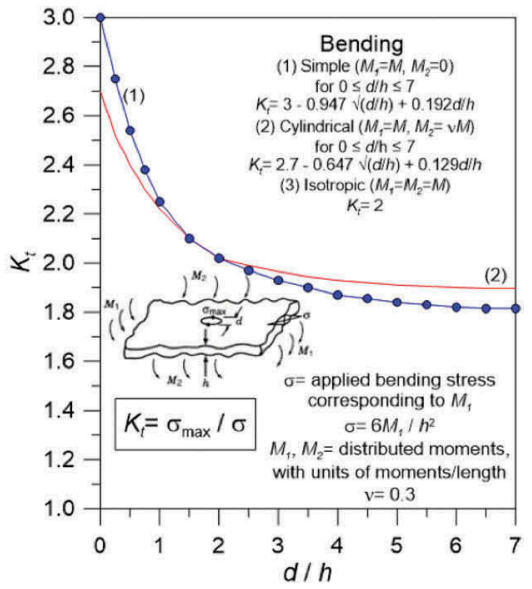

Figure 6. Seismic analysis of stress peaks in the region of holes: a) typical redistribution of seismic forces in the glass walls and b) stress correction factor for bending (figures reproduced from (Bedon et al., 2019) under the terms and conditions of the Creative Commons Attribution (CC BY) license).

a)

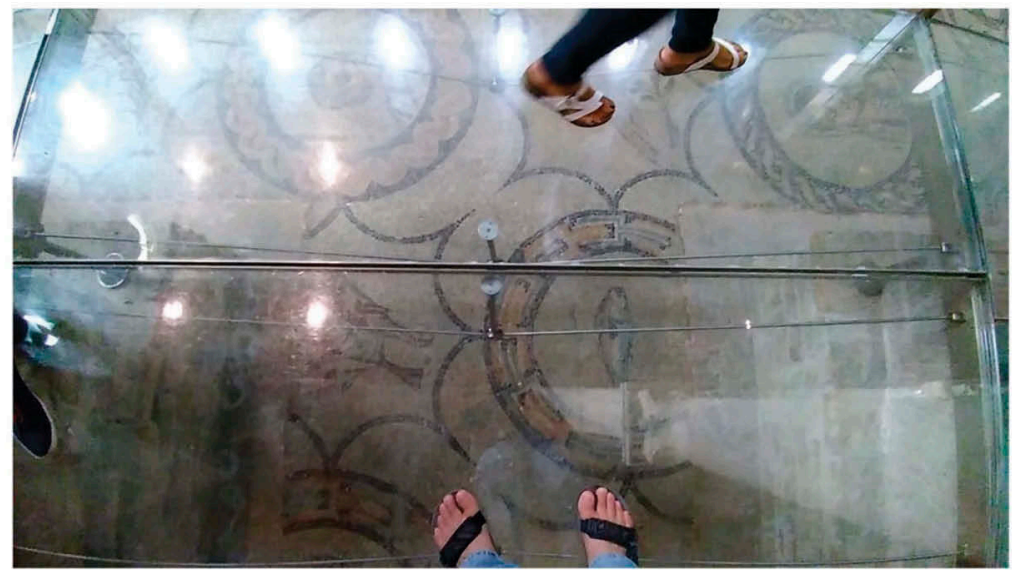

b)

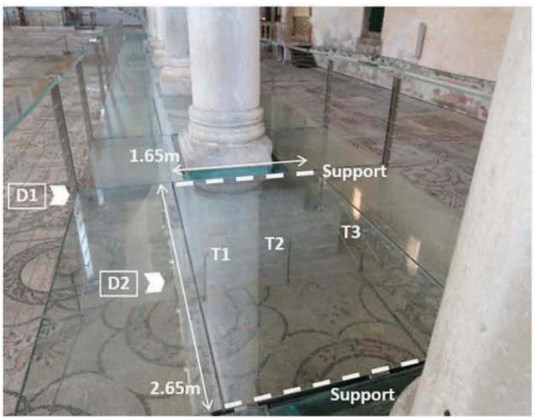

c)

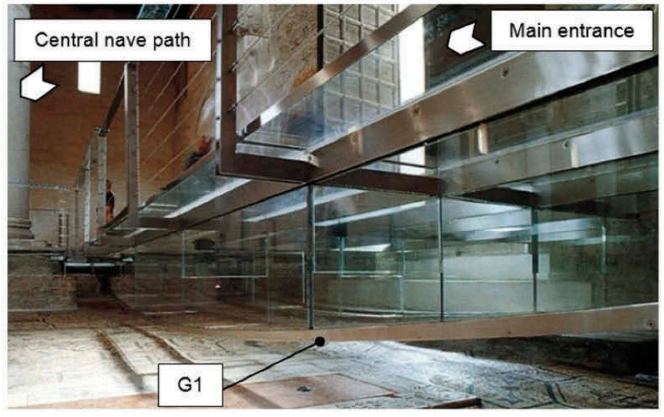

Figure 7. Vibration analysis of an existing in-service glass walkway: a) visual inspection and b) - c) details of the structural system. Figures reproduced from (Bedon \& Fasan, 2019) under the terms and conditions of the Creative Commons Attribution (CC BY) license). 
The vibration analysis in structural glass slabs and roofs includes on the other side some additional uncertainties and difficulties for reliable calculations. First, the structural mass is often lower than the mass of the occupants. Such a primary effect involves a severe modification of the overall structural dynamic response of the system, with consequent variations in the conventional human-structure interaction phenomena. The fundamental vibrations of glass structures are consequently even more sensitive to the presence of standing or moving occupants. Finally, the vibration response of these systems is also affected by time and ambient conditions, given that the interlayers in use to bond the glass panels are subjected to a progressive degradation of stiffness that combines with a further stiffness modification in the same layers (as a direct effect of their viscoelastic nature and response to external induced vibration frequencies).

Recent studies can be found in (Bedon, 2019a; Bedon, 2020), where a case-study system has been investigated with the support of Operational Modal Analysis techniques, Finite Element numerical models, and analytical models of literature that have been properly adapted to the examined boundaries.

The same case-study system was successively explored with a focus on point-fixed glass handrails that are shown in Figure 8 and investigated in (Bedon, 2019b). The vibration analysis of in-service load-bearing members can find further uncertainties and complexities when the actual mechanical properties (i.e., shear rigidity of interlayers) is difficult to quantify due to long-term and high-humidity phenomena (see for example the details in Figure 8a), but also the real restraint effect of fasteners cannot be easily characterized (Figures $8 b-8 c$ ). In this sense, the use of experimental on-site techniques that are typical of the Operational Modal Analysis approaches can offer further support for diagnostics and assessment purposes.

a)
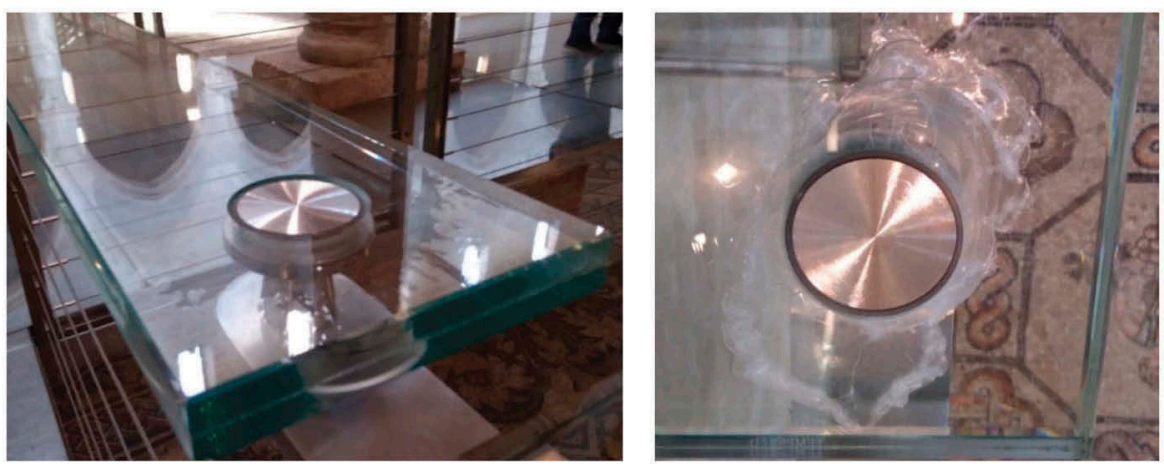

b)

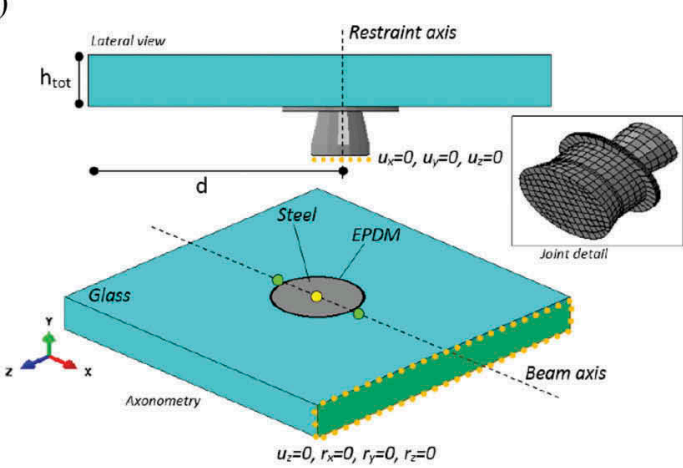

c)

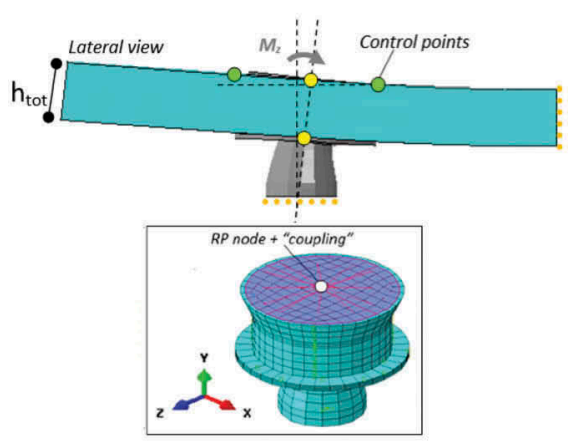

Figure 8. Vibration analysis of point-fixed glass handrails for an existing in-service glass walkway: a) restraint detail, with evidence of delamination and b) - c) selected detail views for the FE numerical analysis (ABAQUS). Figures reproduced from (Bedon, 2019b) under the terms and conditions of the Creative Commons Attribution (CC BY) license). 


\section{CONCLUSIONS}

The use of structural glass member and components in buildings showed a fast increase in the last decades. To this aim, harmonized technical documents and guidelines have been developed (and are still in progress) to support designers and provide fail-safe recommendations of practical use. Besides, the verification and design under extreme design loads and accidental events like impacts and explosions, earthquakes, fire accidents, or even extreme vibrations, still represent an open issue that requires specific calculation and analysis methods. In most of the cases, major challenges are represented by the intrinsic properties of glass and related materials, first of all the viscoelastic interlayers that are used to bond multiple panels together, but also all the secondary components that take place in the region of joints and connections. Furthermore, a glass member itself is required to interact (even with interposed soft layers) with metal frame members of point-fixings and fasteners that could represent a critical region for the prevention of premature stress peaks. As a further important aspect that needs to be properly addressed, is the progressive modification of material properties with variations in the imposed strain rate, vibration frequency, but also time loading, temperature, humidity.

\section{REFERENCES}

Bedon, C., Amadio, C. 2018. Numerical assessment of vibration control systems for multi-hazard design and mitigation of glass curtain walls. Journal of Building Engineering, 15: 1-13.

Bedon, C., Amadio, C., Noé, S. 2019. Safety Issues in the Seismic Design of Secondary Frameless Glass Structures, Safety, 5(4), 80; https://doi.org/10.3390/safety5040080.

Bedon, C., Fasan, M. 2019. Reliability of Field Experiments, Analytical Methods and Pedestrian's Perception Scales for the Vibration Serviceability Assessment of an In-Service Glass Walkway. Applied Sciences, 9(9), 1936; https://doi.org/10.3390/app9091936.

Bedon, C., Fasan, M., Amadio, C. 2019. Vibration Analysis and Dynamic Characterization of Structural Glass Elements with Different Restraints Based on Operational Modal Analysis. Buildings, 9 (1): 13; https://doi.org/10.3390/buildings9010013.

Bedon, C., Zhang, X., Santos, F., Honfi, D., Kozłowski, M., Arrigoni, M., Figuli, L., Lange, D. 2018. Performance of structural glass facades under extreme loads - Design methods, existing research, current issues and trends. Construction and Building Materials, 163: 921-937.

Bedon, C. 2019a. Diagnostic analysis and dynamic identification of a glass suspension footbridge via on-site vibration experiments and FE numerical modelling. Composite Structures, 216: 366-378.

Bedon, C. 2019b. Issues on the Vibration Analysis of In-Service Laminated Glass Structures: Analytical, Experimental and Numerical Investigations on Delaminated Beams. Applied Sciences, 9(18): 3928; https://doi.org/10.3390/app9183928.

Bedon, C. 2020. Experimental investigation on vibration sensitivity of an indoor glass footbridge to walking conditions. Journal of Building Engineering, 29: 101195.

CEN/TC 250. 2019s. prCEN/TS xxxx-1: 2019-In-Plane Loaded Glass Components; CEN-European Committee for Standardization: Brussels, Belgium.

CEN/TC 250. 2019b. prCEN/TS xxxx-2: 2019-Out of-Plane Loaded Glass Components; CEN-European Committee for Standardization: Brussels, Belgium.

CNR-DT 210. 2013. Istruzioni per la Progettazione, L'esecuzione ed il Controllo di Costruzioni con Elementi Strutturali di vetro [Guide for the Design, Construction and Control of Buildings with Structural Glass Elements]; National Research Council of Italy (CNR): Roma, Italy, 2013; available online: www.cnr.it/it/node/2630.

EN 1990. 2005. Eurocode 0 - Basis of Structural Design - Annex A2: Application for Bridges; CEN: Brussels, Belgium.

Förch, M. 2020. Time-Temperature Dependency of Laminated Glass Subjected to Blast Load A Numerical Study. International Journal of Structural Glass and Advanced Materials Research, 4(1): 69-81, https://doi.org/10.3844/sgamrsp.2020.69.81.

Kalamar, K., Bedon, C., Eliášová, M. 2016. Experimental investigation for the structural performance assessment of square hollow glass columns. Engineering Structures, 113 (4), 1-15.

Kozlowski, M., Bedon, C., Honfi, D. 2018. Numerical Analysis and 1D/2D Sensitivity Study for Monolithic and Laminated Structural Glass Elements under Thermal Exposure. Materials, 11(8): 1447, https://doi.org/10.3390/ma11081447. 
Haldimann, M., Luible, A., Overend, M. 2008. Structural Use of Glass; IABSE: Zurich, Switzerland, ISBN 978-3-85748-119-2.

ISO 10137. 2007. Bases for Design of Structures - Serviceability of Buildings and Walkways Against Vibrations; International Organization for Standardization (ISO): Geneva, Switzerland.

Larcher, M., Arrigoni, M., Bedon, C., van Doormaal, A., Haberacker, C., Hüsken, G., Millon, O., Saarenheimo, A., Solomos, G., Thamie, L., Valsamos, G., Williams, A., Stolz, A. 2016. Design of blast-loaded glazing windows and facades: a review of essential requirements towards standardization. Advances in Civil Engineering, https://doi.org/10.1155/2016/2604232.

Sielicki, P.W., Bedon, C., Zhang, X. 2020. Performance of TGU Windows under Explosive Loading. In: Hofreiter L., Berezutskyi V., Figuli L., Zvaková Z. (eds) Soft Target Protection. NATO Science for Peace and Security Series C: Environmental Security, pp. 49-59. Springer, Dordrecht. https://doi.org/ 10.1007/978-94-024-1755-5_4.

Sjöström, J., Kozlowski, M., Honfi, D., Lange, D., Albrektsson, J., Lenk, P., Eriksson, J. 2020. Fire Resistance Testing of a Timber-Glass Composite Beam. International Journal of Structural Glass and Advanced Materials Research, 4(1): 24 40, https://doi.org/10.3844/sgamrsp.2020.24.40.

Zhang, X., Bedon, C. 2017. Vulnerability and Protection of Glass Windows and Facades under Blast: Experiments, Methods and Current Trends. International Journal of Structural Glass and Advanced Materials Research, 1(2), 10-23. https://doi.org/10.3844/sgamrsp.2017.10.23.

Zhang, X., Meng, Q., Bedon, C., Sielicki, P.W. 2020. Strengthening of Laminated Glass Windows against Windborne Debris Impact. International Journal of Structural Glass and Advanced Materials Research, 4(1): 209-224, https://doi.org/10.3844/sgamrsp.2020.209.224. 